\title{
OBSERVATIONS OF SEED-BUG (HEMIPTERA: LYGAEIDAE) PARASITISM BY A SPECIES OF CATHAROSIA (DIPTERA: TACHINIDAE) ${ }^{1}$
}

\author{
By Kevin W. Thorpe ${ }^{2}$ and B. Jane Harrington \\ Department of Entomology \\ University of Wisconsin \\ Madison, Wisconsin 53706
}

\section{INTRODUCTION}

Tachinids of the genus Catharosia Rondani are infrequently collected parasitoids of seed bugs (Hemiptera: Lygaeidae). Sweet (1964) was the first to publish biological information on flies of this genus. He reared Catharosia from 15 species of bugs in 11 genera and, after communicating with Dr. Paul H. Arnaud, Jr., concluded that a large complex of Catharosia species was probably involved. Later Ashlock and O'Brien (1964) reported rearing 35 Catharosia lustrans (Reinhard) from field collected Thylochromus nitidulus (Barber) and Eremocoris opacus Van Duzee (Lygaeidae: Rhyparochrominae: Drymini). These authors also reared a single fly through a complete life cycle on a laboratory culture of an undescribed species of Eremocoris.

During the summers of 1977 and 1978, we reared 51 adults of a tachinid species from field collected individuals of four closely related lygaeid genera of the rhyparochromine tribe Myodochini. We reared an additional 16 flies through a complete life cycle on laboratory cultured Ligyrocoris diffusus (Uhler). Samples from these rearings were identified as a single species of Catharosia (P.H. Arnaud, personal communication). Voucher specimens were deposited in the collections of the California Academy of Sciences, San Francisco and the University of Wisconsin, Madison.

\footnotetext{
${ }^{1}$ Research supported by the College of Agricultural and Life Sciences, University of Wisconsin-Madison and by a grant from the University of Wisconsin Graduate School (Project Number 190381). Part of a thesis submitted by K. Thorpe in partial fulfillment of the requirements for the MS degree.

${ }^{2}$ Present Address: Beneficial Insect Introduction Laboratory, Building 417, BARC-East, Beltsville, Maryland 20705.

Manuscript received by the editor May 6, 1980.
} 
From that rearing effort we present information on the biology of this parasitoid and a description of an interesting structure on the female abdomen that presumably aids in oviposition.

\section{Materials ANd Methods}

Lygaeid adults and nymphs were collected from several dry, disturbed habitats in each of three Wisconsin counties. Ligyrocoris diffusus and Perigenes constrictus (Say) were collected from Dane Co. in southern Wisconsin; L. diffusus, $L$. sylvestris (L.), $P$. constrictus, Sphaerobius insignis Uhler, and Zeridonius costalis (Van Duzee) were collected from Wood Co. in central Wisconsin; and $L$. diffusus, L. sylvestris, and Z. costalis were collected from Vilas Co. in northern Wisconsin. Field collected bugs were maintained and reared individually or in small conspecific groups at $26 \pm 1^{\circ} \mathrm{C}$ and 16L:8D photoperiod in glass crystalizing dishes $(90 \times$ $50 \mathrm{~mm}$ ) with plastic lids. Each dish was provided with a vial of water stoppered with a dental wick, hulled sunflower seeds, and several thin squares of methyl cellulose. The dishes were checked daily for tachinid pupae, which were transferred to clean vials to prevent fungus infestation. Upon eclosion adult flies were supplied with a dental wick moistened with sugar water. Whenever both sexes of flies became available concurrently they were placed together with laboratory cultured $L$. diffusus nymphs and adults.

Scanning electron photomicrographs of Catharosia were obtained from gold-palladium-coated preparations viewed on a Jelco JSMU3 scanning electron microscope.

\section{Results AND Discussion}

Catharosia were reared from all myodochine species collected in Wood Co. and Vilas Co., but none emerged from any bugs collected in Dane Co. Ligyrocoris sylvestris is a new host record for the genus Catharosia. Sweet (1964) reported rearing Catharosia from $L$. diffusus and $L$. dipictus Barber in New England, but not from $L$. sylvestris or $L$. caracis Sweet. Sweet also reported rearing Catharosia from the other 3 myodochine species collected in this study.

The rates of parasitism of $L$. diffusus, the myodochine most commonly collected at the Wood Co. site on 19 June and 22 August 1978 , were $60 \%$ and $16 \%$ respectively (Table 1 ). The difference in 
rates of parasitism between the sexes of L. diffusus (summed across both collection dates) was not significant at the .05 level.

Table 1. Rates of parasitism by Catharosia in L. diffusus collected on 2 separate dates in 1978 in Wood Co., Wisconsin.

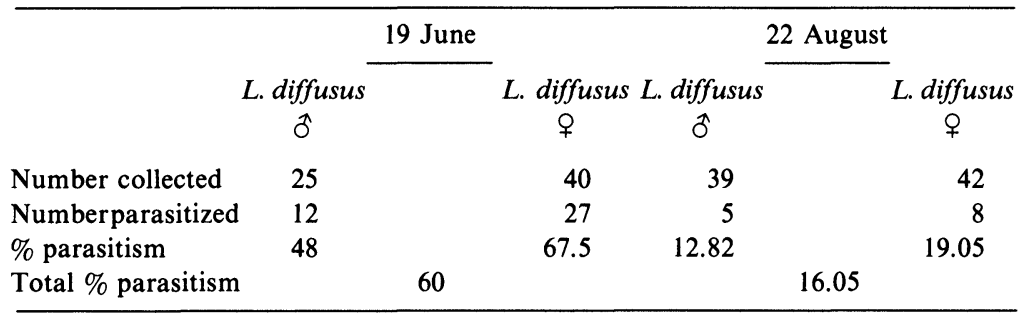

Laboratory reared flies began mating on the day of eclosion. There was no apparent, regular courtship ritual. However, males appeared to orient visually to females and both sexes frequently flicked their wings upward while running, displaying the white apex of the wing which contrasts sharply with the darker basal portion. This wing flicking behavior may serve in some sort of intraspecific visual communication. Copulating males placed their foretarsi over the females' eyes but no special adaptations of the male foretarsi were discernible. The duration of copulation ranged from a few seconds to several minutes, and copulation was often repeated by single pairs at short intervals.

Examination of female flies revealed an interesting structure located on the fourth abdominal sternum (Fig. 1). It consists of paired plates on either side of the midline covered by a field of spines directed medially and slightly caudad. The presence of this structure was previously noted by Lundbeck (1927) who described the fourth sternum of Catharosia as "cleft in the middle and covered with short spinules." Although oviposition was not observed during our rearing efforts, the needle-like nature of the Catharosia ovipositor (or larvapositor) suggests subcutaneous deposition of either eggs or larvae into the host. The spined plates probably aid in holding the host during oviposition. A similar structure is found on tachinids of the genus Celatoria which parasitize beetles in the family Chrysomelidae, however the structure in this case is located on the apex of a laterally compressed tubercle that extends ventrally from the second abdominal segment and opposes the larvapositor 
(Bussart 1937, Walton 1914). Walton suggests that the function of this structure is to hold the host in place as the larvapositor is forced through the beetle's elytra. These ovipositor opposing structures of Celatoria and Catharosia probably represent convergent evolution of organs serving similar functions but located on different abdominal segments.

Catharosia was found to parasitize both adult and nymphal mydochine bugs, but parasitoids only emerged from adult hosts. One fifth instar $L$. diffusus nymph collected in the field yielded a Catharosia after the bug had molted to an adult. All other Catharosia obtained from field collected hosts were reared from hosts collected as adults.

In laboratory reared flies total development time from first mating of parent flies until adult progeny eclosed averaged 23.5 days $(\mathrm{SE}=1.15$, Range $=18-29, \mathrm{~N}=15)$. These data agree with the observed development time of the parasitoids reared from field collected hosts.

The position of Catharosia larvae within the host was determined

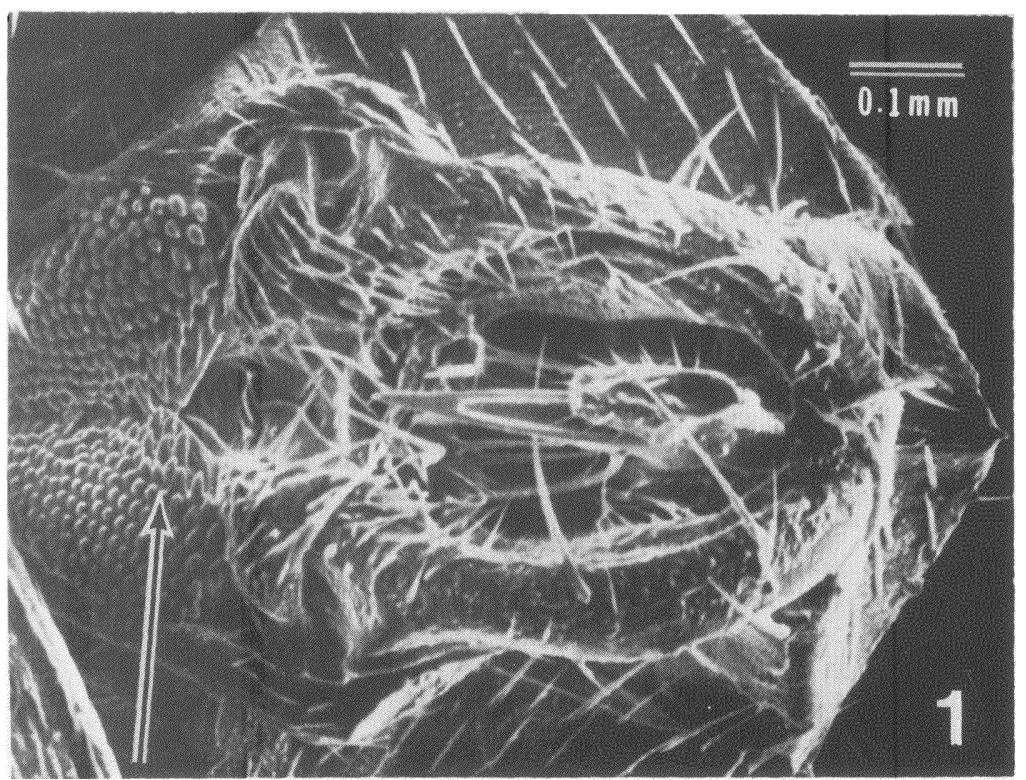

Figure 1. Scanning electron photomicrograph of ventral abdominal surface of a Catharosia sp. female showing heavily spined plates on 4th sternum. 
from dissections of twenty parasitized $L$. diffusus. Figure 2 depicts the position of a mature third instar larva within an adult $L$. diffusus female. The full grown larva fills the entire abdominal cavity and its posterior spiracle partially protrudes into the bug's thorax where it fits into a respiratory funnel (Clausen (1940) discussed the host tissue origins of such a respiratory funnel). The host-attached, narrow end of the funnel was always found lying very close to either the right (12 examples) or left (8 examples) metathoracic spiracle, and was probably attached to the spiracular stalk not far from the spiracle.
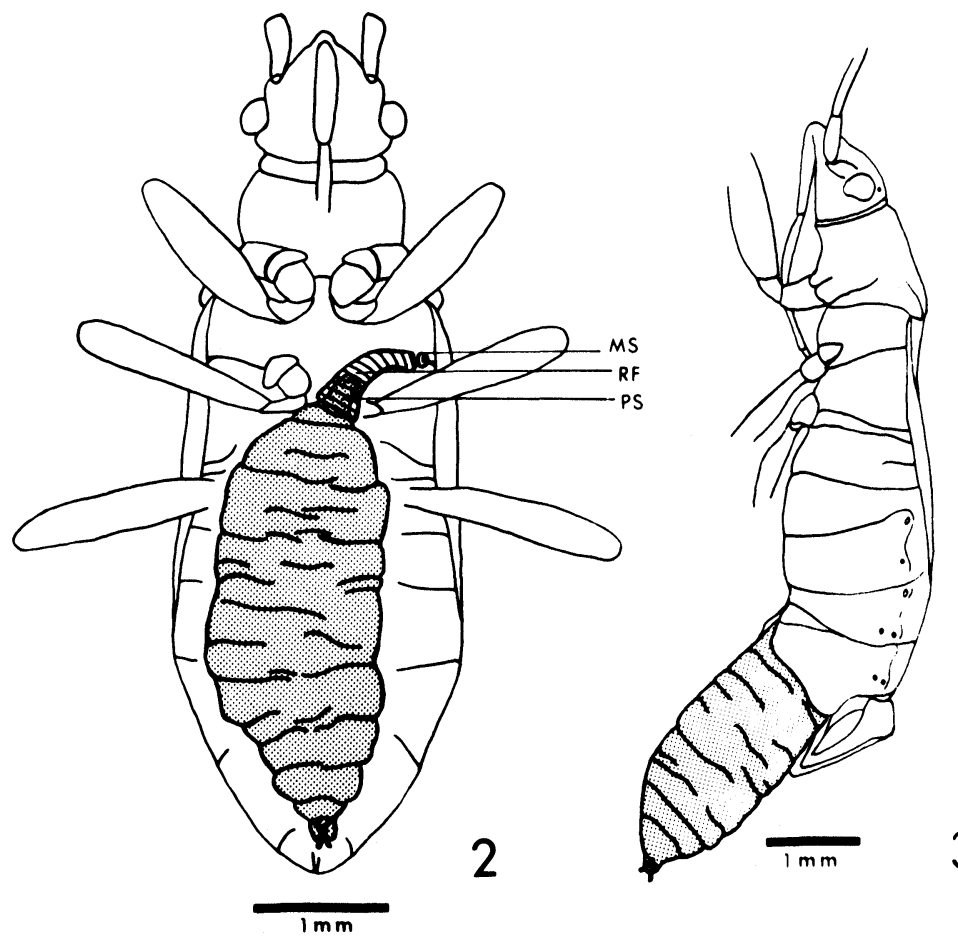

Figure 2. Mature Catharosia sp. larva within L. diffusus female. Note respiratory funnel attached near host's metathoracic spiracle $(\mathrm{MS}=$ metathoracic spiracle of $L$. diffusus; $\mathrm{RF}=$ respiratory funnel; $\mathrm{PS}=$ posterior spiracle of Catharosia larva).

Figure 3. Mature Catharosia larva emerging from $L$. diffusus female. Larva is passing beneath ovipositor through cleft in center of host's 7 th abdominal sternum. 
Mature Catharosia larvae emerge by rupturing the intersegmental membrane between the eighth abdominal segment and the pygophore in male hosts, and the seventh sternum and the first valvifers in female hosts. After the larva has passed through, the host's sclerites typically fall back into place, making it difficult to recognize that a parasitoid has emerged. During our study one larva died while emerging from a female $L$. diffusus, providing an opportunity to examine closely how an exit is achieved (Fig. 3). Bugs sometimes lived for several days after the emergence of a fly larva, and Ashlock and O'Brien (1964) reported one female lygaeid (sp?) living for a month after the emergence of a Catharosia lustrans larva. This bug produced five eggs, but development of the parasitoid may have been abnormal since the larva died without forming a puparium. Other dissections by these authors and all of our dissections revealed that fully developed gonads are not present in parasitized hosts.

Upon emerging from the host the mature larva moves a short distance away and pupates. Puparia were occasionally found lying in the open on the substrate. However, pupation usually occurred beneath some sort of cover.

The high rate of parasitism found in the Wood Co. L. diffusus population when sampled on 19 June $1978(60 \%)$ and the laboratory dissections, which indicate that Catharosia sterilizes its host, suggest that this fly may play an important role in controlling seed bug populations.

\section{SUMMARY}

Fifty-one adults of Catharosia sp. (Diptera: Tachinidae) were reared from Ligyrocoris diffusus (Uhler), L. sylvestris (L.) (new host record for the genus Catharosia), Perigenes constrictus (Say), Sphaerobius insignis Uhler, and Zeridonius costalis (Van Duzee) that were collected in Wisconsin in 1977 and '78. Sixteen flies were reared through a complete life cycle on laboratory cultured $L$. diffusus. Rates of parasitism in field collected $L$. diffusus were $60 \%$ on 19 June and $16 \%$ on 22 August 1978. The fourth sternum of female flies is modified with spined plates that may help hold the host during oviposition. Both adults and nymphs are parasitized, but parasitoids emerge only from adult hosts. Total parasitoid development time can be as short as 18 days. Mature Catharosia 
larvae occupy almost the entire host abdomen and extend into the thorax, where a respiratory funnel forms a connection to the host's tracheal system. Parasitized hosts are usually sterile.

\section{ACKNOWLEDGEMENTS}

We thank Dr. Paul H. Arnaud, Jr. (Department of Entomology, California Academy of Sciences) for examining and identifying our tachinid specimens and Mr. Martin B. Garment (Scanning Electron Microscope Facility, Department of Entomology, University of Wisconsin-Madison) for his skilled assistance with the SEM photomicrograph.

\section{Literature Cited}

Ashlock, P.D. AND C.W. O'Brien.

1964. Catharosia lustrans, a tachinid parasite of some drymine Lygaeidae (Diptera \& Hemiptera-Heteroptera). Pan-Pacific Ent. 40: 98-100. BusSART, J.E.

1937. The bionomics of Chaetophleps setosa Coquillett (Diptera: Tachinidae). Ann. Entomol. Soc. Amer. 30: 285-295.

Clausen, C.P.

1940. Entomophagous Insects. McGraw-Hill, New York. 688 pp. LUNDBECK, W.

1927. Diptera Danica. Genera and Species of Flies Hitherto Found in Denmark. Vol. 7: Platypezidae-Tachinidae, Copenhagen. 517 pp.

SWEET, M.H.

1964. The biology and ecology of the Rhyparochrominae of New England (Heteroptera: Lygaeidae). Parts I \& II. Entomol. Amer. 43: 1-124; 44: 1-201.

WALTON, W.R.

1914. A new tachinid parasite of Diabrotica vittata. Entomol. Soc. Wash. Proc. 16: 11-14. 

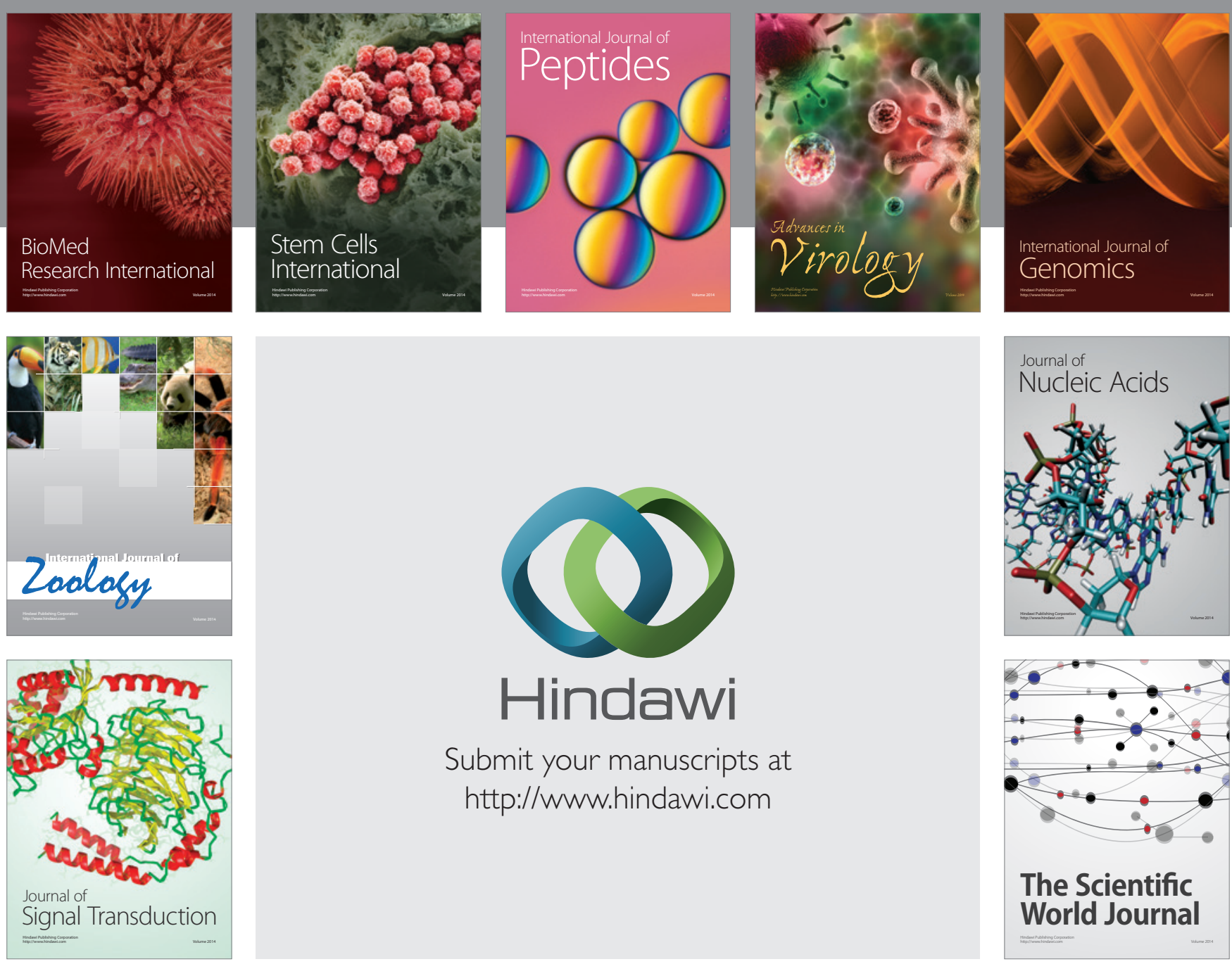

Submit your manuscripts at

http://www.hindawi.com
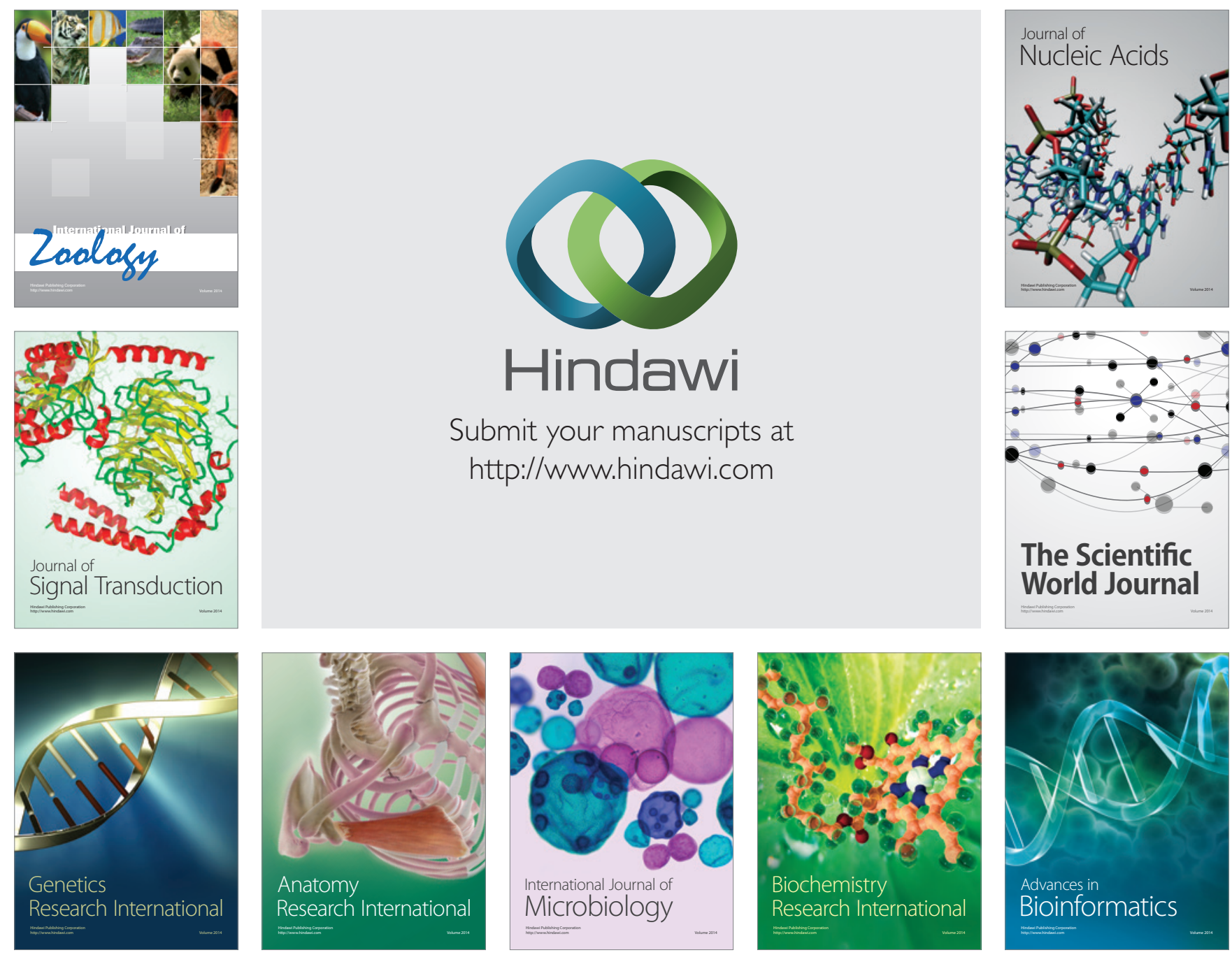

The Scientific World Journal
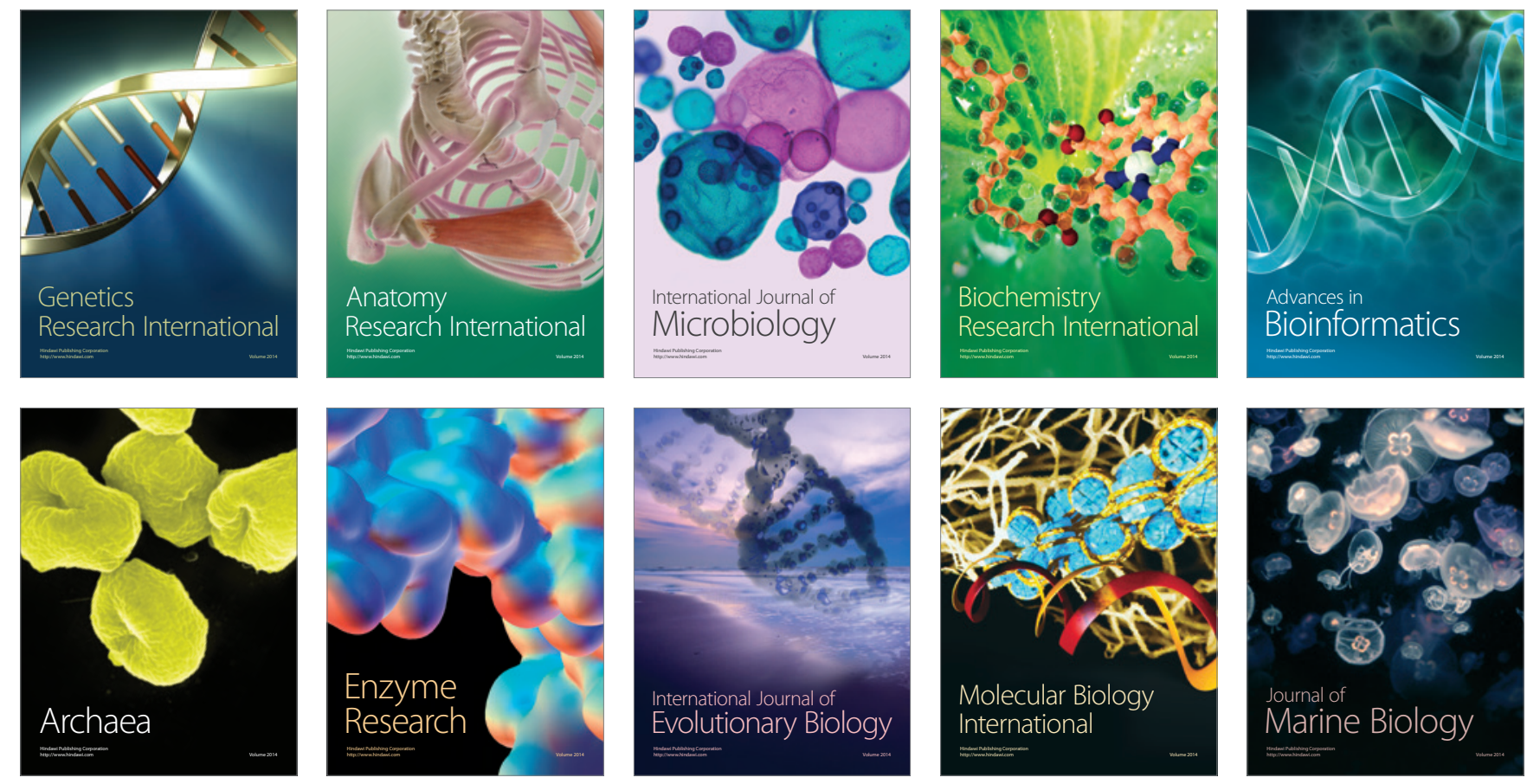